\title{
Social Data for Social Good and a Biased Perspective on Research Impact
}

\author{
Keynote Talk
}

\author{
Alexandra Olteanu \\ IBM T.J. Watson Research Center \\ alexandra.olteanu@ibm.com
}

\section{ABSTRACT}

The ever-growing datasets of user activity traces promise to offer captivating insights into human phenomena. Yet, these datasets are more than just an observational tool. The insights derived from them are increasingly being used to drive policies, to shape products and services, and for automated decision making. It is therefore also important to understand the limitations around their use, especially when they are used to tackle significant societal challenges, such as humanitarian crises, climate change, minority issues, hate speech, and health - social good applications that we will be overviewing in this talk.

I will end the talk with a brief viewpoint on research paths and impact.
\end{abstract}

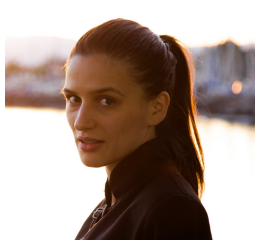

Alexandra Olteanu is a computational social science and social computing researcher and a Data Science for Social Good Fellow at the IBM T.J. Watson Research Center. She is interested in how data and methodological limitations delimit what we can learn from online social traces. The problems she tackles are motivated by existing societal challenges such as hate speech, racial discrimination, climate change, and disaster relief. Her work has won two best paper awards (WISE 2014, Eurosys' SNS workshop 2012), and has been featured in the UN OCHA's "World Humanitarian Data and Trends" and in popular media outlets. More recently, she co-authored a survey of biases and methodological pitfalls when working with online social data, and has been co-organizing several tutorials on the topic at a variety of major data mining, and web and social media conferences, including ICWSM, KDD, WSDM, WWW, and SDM. She has been serving on the program committees of the main social media and web conferences, including ICWSM, WWW, WebSci, CIKM, and SIGIR.

Permission to make digital or hard copies of part or all of this work for personal or classroom use is granted without fee provided that copies are not made or distributed for profit or commercial advantage and that copies bear this notice and the full citation on the first page. Copyrights for third-party components of this work must be honored For all other uses, contact the owner/author(s).

The Second Women in Data Science (WinDS) Workshop, co-located with The Web Confer ence 2018, April 24, 2018, Lyon, France.

(c) 2018 Copyright held by the owner/author(s)

https://doi.org/10.18122/winds/3/boisestate 